\title{
GEODIVERSIDADE E GEOTURISMO NO MUNICÍPIO DE APODI/RN: O CASO DO LAJEDO DE SOLEDADE
}

Geodiversity and geotourism in the municipality of Apodi/RN: a case of Soledade's Lajedo

\author{
ALVES ${ }^{1}$, J. J. F.; MEDEIROS², W. D. A.; TARGINO³, D. R. \\ jessica_jessiana@hotmail.com
}

\section{Resumo}

Este artigo objetiva apresentar os principais aspectos da geodiversidade do Lajedo de Soledade no município de Apodi/RN com foco em sua potencialidade geoturística. Os procedimentos metodológicos estão fundamentados em trabalho de campo e pesquisa bibliográfica. São apresentados os aspectos da geodiversidade e a importância de sua conservação, como rochas, formas de relevo e seus elementos associados como sítios arqueológicos e paleontológicos. Por fim, sugere-se um planejamento prévio para desenvolvimento do geoturismo.

Palavras-chave: Patrimônio geológico. Sítio arqueológico. Turismo.

\begin{abstract}
This paper presents the main aspects of Soledade's Lajedo geodiversity in the municipality of Apodi/RN focused on your potential for the geotourism. The methodological procedures are based on field work and literature. Are presented aspects of geodiversity and importance of your conservation, as rocks, landforms and yours associated elements such as archaeological and paleontological sites. Finally, it is suggested a prior planning for the development of geotourism.
\end{abstract}

Keywords: Geological heritage. Archeological site. Tourism.

\section{INTRODUÇÃO}

O termo geodiversidade surgiu em meados da década de 1940, sendo definido pelo geógrafo argentino Frederico Alberto Daus, como a diversidade geográfica dos lugares (CAÑADAS; RUIZ FLAÑO, 2007). Porém, o termo começou a ser mais divulgado a partir da Conferência de Malvern sobre Conservação Geológica e Paisagística que ocorreu no Reino Unido em 1993 (BENTO; RODRIGUES, 2010).

A geodiversidade envolve predominantemente os elementos abióticos do meio ambiente, isto é, envolve os elementos do meio físico. Esta concepção é seguida pelo Serviço Geológico do Brasil (CPRM) que define a geodiversidade como

"uma variedade de ambientes, composição, fenômenos e processos geológicos que dão origem às paisagens, rochas, minerais, águas, fósseis, solos, clima e outros depósitos superficiais que propiciam o desenvolvimento da vida na Terra, tendo como valores intrínsecos a cultura, o estético, o econômico, o científico, o educativo e o turístico" (CPRM, 2010).

\footnotetext{
${ }^{1}$ Jessica Jessiana Ferreira Alves, Departamento de Gestão Ambiental, Universidade do Estado do Rio Grande do Norte, MossoróRN, Brasil.

${ }^{2}$ Wendson Dantas de Araújo Medeiros, Departamento de Gestão Ambiental, Universidade do Estado do Rio Grande do Norte, Mossoró-RN, Brasil.

${ }^{3}$ Dinária Rafaela Targino, Departamento de Gestão Ambiental, Universidade do Estado do Rio Grande do Norte, Mossoró-RN, Brasil.
} 
Nascimento et al. (2009) fazem uma relação entre geodiversidade e patrimônio geológico, onde o conceito de patrimônio geológico, que é representado pelo conjunto de sítios geológicos, também chamados de geossítios, está estreitamente relacionado com a geodiversidade. Contudo, não se deve encarar o patrimônio geológico como sinônimo de geodiversidade. A geodiversidade, de forma simples, consiste em toda a variedade de minerais, rochas, fósseis e paisagens que ocorre no planeta Terra, enquanto o patrimônio geológico é apenas uma pequena parcela da geodiversidade apresentando características especiais e que, por conseguinte, deve ser conservado.

Nesse sentido, percebe-se que a geodiversidade apresenta um conteúdo por meio das suas expressões que, em conjunto, significam importantes registros do tempo geológico da Terra, configurando-se como um arquivo do passado geológico, geomorfológico, mineralógico, pedológico, climático e paleontológico (MANOSSO; ONDICOL, 2012).

Como tem natureza concreta, os elementos da geodiversidade constituem bens não renováveis. Uma vez deteriorados não podem mais ser recuperados, o que exige cuidados especiais visando à sua preservação para as gerações presente e futura. Entre esses cuidados, destaca-se a necessidade de conscientização da população acerca de sua importância, valores e representatividade. Tal conscientização pode se dar por meio da atividade turística, especialmente pelo geoturismo, uma vez que os elementos da geodiversidade (rochas, formas, processos etc.) constituem verdadeiros atrativos turísticos.

De acordo com Medeiros e Oliveira (2011), o Geoturismo se trata da atividade voltada à visitação de elementos da geodiversidade, buscando o conhecimento geocientífico associado aos geossítios ou elementos representativos da geologia, geomorfologia, paleontologia, mineralogia entre outros que constituem a geodiversidade. Além destes, o geoturismo se apropria também de elementos culturais e bióticos, que muitas vezes só existem em um dado local em razão da contribuição da geodiversidade. No entanto, esses autores destacam que a diferença entre o Geoturismo e outros tipos de turismo está na motivação da viagem, que deve estar relacionada ao conhecimento da geodiversidade de um dado lugar (Op. cit.).

O geoturismo é, portanto, uma atividade do turismo com conotação geocientífica, ou seja, é a visita organizada e orientada a locais onde ocorrem recursos do meio físico, que testemunham uma fase do passado ou da história de origem e evolução do planeta Terra, incluindo, também, o conhecimento científico sobre a gênese da paisagem, processos envolvidos e testemunhos registrados em rochas, solos e relevos (SILVA; PERINOTTO, 2007).

Nesse contexto, o presente artigo aborda a questão da geodiversidade e do geoturismo no município de Apodi/RN, situado na mesorregião Oeste Potiguar, voltado especificamente para o Lajedo de Soledade, importante atrativo turístico da região e um importante patrimônio geológico 
do estado do Rio Grande do Norte. Tem como principal objetivo apresentar os principais aspectos da geodiversidade do Lajedo Soledade com foco em sua potencialidade geoturística.

\section{PROCEDIMENTOS METODOLÓGICOS}

Os procedimentos metodológicos estão apoiados basicamente em pesquisa bibliográfica e trabalho de campo, que segundo Gil (2008), procura o aprofundamento de uma realidade específica, sendo realizada por meio da observação direta.

A pesquisa se fundamenta numa abordagem qualitativa, onde foram realizadas observações in loco com registros fotográficos na área de estudo. Os dados obtidos em campo foram consubstanciados através de leituras de diversos materiais como artigos, livros, teses e dissertações, visando também a realizar uma breve caracterização da área. Isso se faz necessário, pois tem a importância de aumentar a extensão e a profundidade dos conteúdos conhecidos e estudados (MARTINS, 2010).

\subsection{Breve caracterização da área de estudo}

O Lajedo de Soledade fica localizado no Município de Apodi/RN, na mesorregião Oeste Potiguar e microrregião Chapada do Apodi, Nordeste do Brasil. O município possui uma área de $1.602,479 \mathrm{~km}^{2}$, com uma população estimada de 36.189 habitantes (IBGE, 2015), limitando-se com os municípios de Governador Dix-Sept Rosado, Felipe Guerra, Umarizal, Itaú, Severiano Melo, Caraúbas, além do Estado do Ceará (IDEMA, 2005). A sede do município fica localizada a aproximadamente $340 \mathrm{~km}$ de Natal/RN, e a $323 \mathrm{~km}$ de Fortaleza/CE.

O Lajedo de Soledade está localizado na comunidade homônima, distando cerca de $12 \mathrm{~km}$ do centro da cidade de Apodi e cerca de $76 \mathrm{~km}$ da cidade de Mossoró (Figura 01). O acesso à área de estudo se dá pela BR-304, a partir de Mossoró ou Apodi e continua por uma via asfaltada até a comunidade de Soledade. A origem do nome Soledade, ainda é desconhecida. Porém, de acordo com muitos moradores locais, o nome faz referência a uma das primeiras habitantes do local, uma senhora que se chamava "Solídon”, e daí passaram a chamar a comunidade com um termo parecido, Soledade.

Do ponto de vista natural, a área apresenta um clima do tipo muito quente e semiárido, caracterizado por curta estação chuvosa concentrada entre os meses de março a maio. As médias pluviométricas anuais giram em torno de $717 \mathrm{~mm}$, com temperatura média anual em torno de $28.1^{\circ} \mathrm{C}$ e umidade relativa média anual de 68\% (IDEMA, 2008). Geologicamente, o município de Apodi 
está inserido na área da Bacia Potiguar, que se destaca nacionalmente por ser a principal área de produção de petróleo em terra do Brasil. As litologias predominantes associadas a esta extensa bacia sedimentar estão relacionadas aos arenitos da Formação Açu, do Cretáceo inferior, e aos calcários da Formação Jandaíra, do Cretáceo superior (CPRM, 2008). Do ponto de vista geomorfológico, integra áreas da Chapada do Apodi e da Depressão Sertaneja. As altitudes são modestas, sempre inferiores a 100 m (IDEMA, 2008) e os terrenos são predominantemente planos, nas áreas da Chapada e de plano a suavemente ondulados nas áreas da Depressão Sertaneja. Porém, o limite de contato entre a Chapada do Apodi e a Depressão Sertaneja forma declives abruptos e marcam os principais contrastes topográficos da área de estudo. Os tipos de solos que ocorrem na área são argissolos, cambissolos, chernossolos, luvissolos e neossolos (EMBRAPA, 2006).

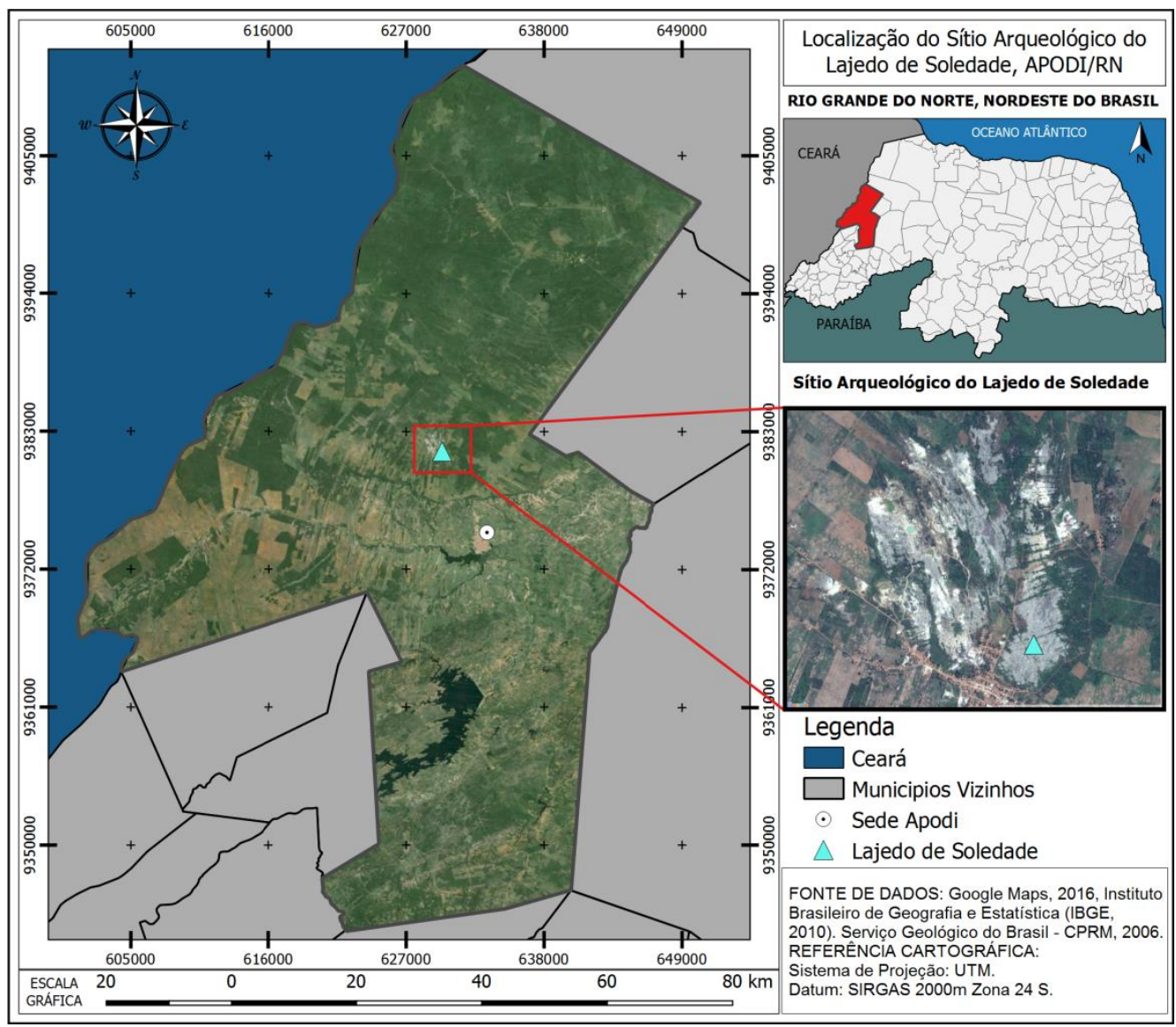

Figura 01. Localização do Lajedo de Soledade. Fonte: Elaborado por Dinária Rafaela, 2016.

De acordo com o CPRM (2008), o município de Apodi encontra-se totalmente inserido nos domínios da bacia hidrográfica Apodi-Mossoró, sendo banhado pela sub-bacia do Rio Apodi, que o atravessa em sua porção central, no sentido SW/NE.

Especificamente na área do Lajedo de Soledade, a litologia dominante é o calcário Jandaíra e o relevo se encontra predominantemente plano, típico da Chapada do Apodi. As principais exceções estão nas diversas ravinas encontradas no lajedo, derivadas de processos de intemperismo, 
erosão e dissolução carbonática. Junto com isso, várias outras formas relacionadas aos ambientes cársticos são encontradas, como pequenas dolinas, grutas e cavernas.

O quadro vegetacional é marcado pelo domínio da caatinga em grande parte do município, e na área do lajedo, com ocorrência de jurema-preta, mufumbo, faveleiro, marmeleiro, xiquexique e facheiro. Apenas nas várzeas do rio Apodi e da lagoa do Apodi e nas baixadas húmidas, percebe-se a ocorrência da floresta ciliar de Carnaúba (IBGE, 2002).

Quanto à economia, as atividades predominantes são a agricultura, onde se desenvolvem lavouras temporárias (algodão herbáceo, arroz, feijão e milho) e permanentes (caju e banana). Tais culturas apresentam baixa produtividade, pois são estabelecidas sob o regime de dependências de chuvas, com o uso de tecnologias muito simples. A pecuária constitui uma significativa atividade econômica, com predominância da caprinovinocultura e da bovinocultura (SEMARH, 2007). Destaca-se, ainda, a presença da empresa PETROBRAS, que explora petróleo e gás natural em áreas da Chapada do Apodi. O turismo ainda é incipiente e apoia-se basicamente na realização de eventos, como o Carnaval e festejos religiosos. Contudo, o Lajedo de Soledade tem se mostrado um importante atrativo turístico, recebendo turistas ao longo de todo o ano, sobretudo relacionado ao turismo pedagógico.

\section{ASPECTOS DA GEODIVERSIDADE E POTENCIAL GEOTURÍSTICO DO LAJEDO DE SOLEDADE}

A geodiversidade, enquanto testemunho científico dos acontecimentos que marcaram a história evolutiva da Terra, deve ser conservada como parte fundamental do patrimônio natural e utilizada para fins científicos, didáticos, culturais e geoturísticos (GODOY et al., 2013). O Lajedo de Soledade se enquadra nesse contexto, pois possui a maior exposição de rocha calcária da Bacia Potiguar (BAGNOLI, 1994) e apresenta registros geológicos, geomorfológicos, paleontológicos e arqueológicos que permitem evidenciar, didaticamente, o conhecimento geocientífico relacionado à sua evolução ao longo do Tempo Geológico e histórico. Esses registros reforçam a sua potencialidade geoturística.

O Lajedo é caracterizado por um vasto afloramento calcário da formação Jandaíra (figura 02), do período Cretáceo, com idade geológica estimada em 90 milhões de anos (BAGNOLI, 1994). Nesse período a região encontrava-se coberta por um mar raso, que recuou devido à separação dos continentes africano e sul-americano, restando sedimentos. De acordo com Porpino et al. (2004), esses sedimentos, já compactados em rochas, foram soerguidos com relação ao nível do mar e expostos à erosão desde o final do Mesozoico (Mesocampaniano). O Lajedo encontra-se recortado por diversas falhas e fraturas de direção preferencial NE-SW e NW-SE, as quais permitiram o 
desenvolvimento de ravinas e cavernas a partir de intenso processo de carstificação (PORPINO et al., 2004).

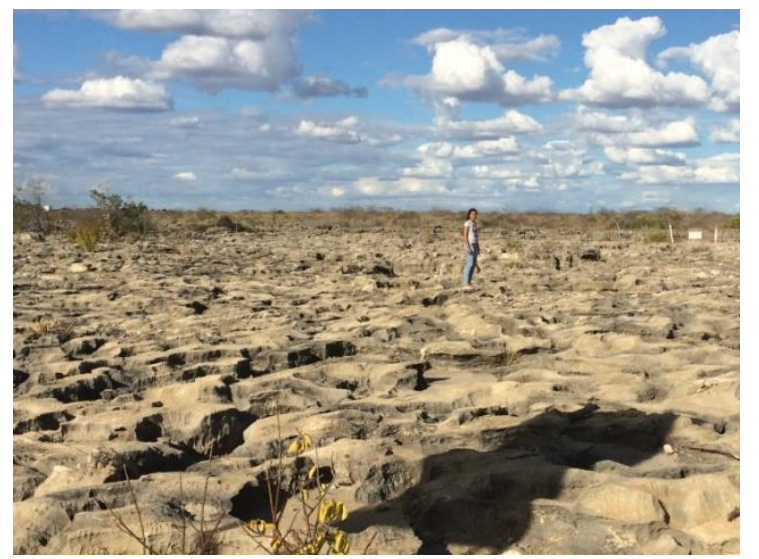

Figura 02. Afloramento calcário, Lajedo de Soledade. Fonte: Jessica Alves, 2016.

Dentre as cavernas, o Lajedo possui duas que estão entre as maiores do Estado do Rio Grande do Norte: a Gruta do Roncador, que possui 480 metros de extensão, considerada a maior do Estado; e, a Gruta do Peninha, com 46 metros de extensão (SBE, 2016). Estas cavernas são hoje preservadas e podem vir a ser utilizadas pelo geoturismo, desde que de forma responsável e mediante um planejamento prévio que envolva estudos de capacidade de carga e que promova a sua conservação.

Apesar de estar dentro da área preservada, que totaliza 10 ha do total de 127 ha de área do Lajedo, há uma forte pressão antrópica sobretudo ligada ao avanço da atividade de extração mineral do calcário voltado à indústria da cal e do cimento, que hoje são de suma importância para a economia da localidade e do município. A preservação ambiental dessa área só foi possível mediante longa campanha de conscientização da população local, visto que a integridade do local estava ameaçada, principalmente por se tratar de um recurso natural não renovável com valor científico, cultural, educativo e econômico (CPRM, 2010).

A área preservada é dividida em três áreas de visitação turística: 1) Araras, a mais conhecida e visitada por turistas; 2) Urubu, que é bastante procurada no período chuvoso por formar uma espécie de cachoeira; e 3) a área do Olho d'água, que possui várias lendas contadas por moradores locais e que reforçam a sua potencialidade geoturística, haja vista que esta atividade permite a integração do conhecimento geocientífico com o conhecimento tradicional e popular, que se mantém por meio de tradições orais, passando de geração a geração e se constituindo importante patrimônio imaterial a ser trabalhado pelo geoturismo.

A área das Araras possui forte potencialidade geoturística reforçada pela integração dos elementos geológicos e geomorfológicos com sítios arqueológicos. Nessa área são encontrados vários painéis com pinturas rupestres da tradição Agreste (MARTIN, 2000) (figura 03), povos pré- 
históricos que habitaram a região por volta de 5.000 a 2.500 anos antes do presente (MARTIN, 2000), provavelmente em busca de água e alimento, e acabaram por deixar seus registros na rocha, deixando uma história a ser contada. Sendo assim, o geoturismo possibilita conhecer aspectos relacionados à formação da rocha e evolução de suas formas ao longo do Tempo Geológico envolvendo milhões de anos e integrando ao uso dessas formas por povos pré-históricos há poucos milhares de anos.

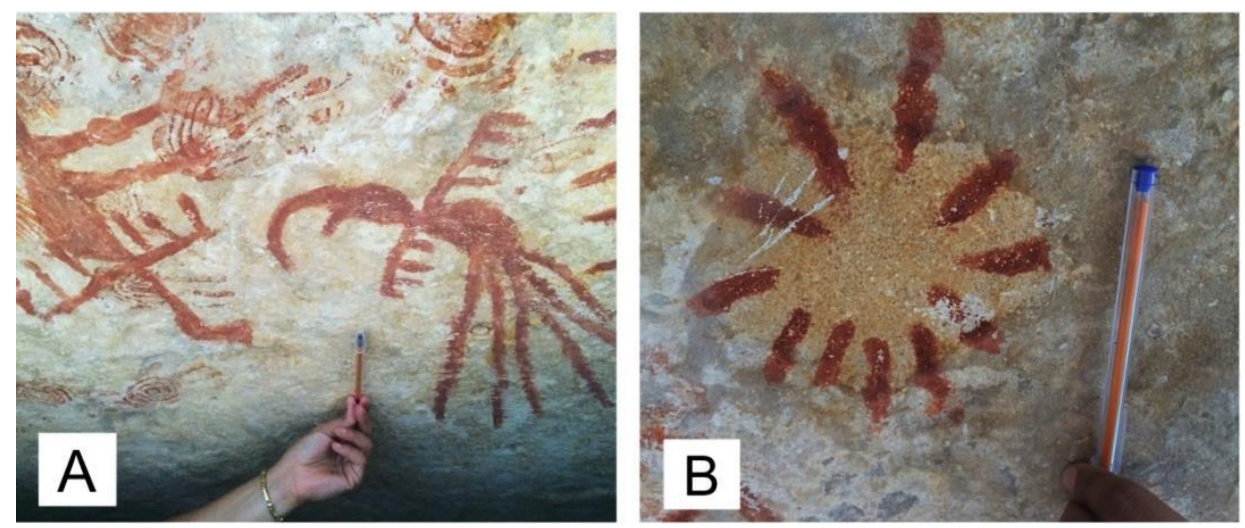

Figura 03. Pinturas rupestres no painel das Araras, com destaque para a Arara (A) e pintura que lembra o Sol (B). Fonte: Dinária Rafaela, 2016.

As pinturas são encontradas principalmente na cor vermelha, mas também ocorrem nas cores amarela e preta. Além destas, também ocorrem gravuras em vários locais do Lajedo (figura 04). Boa parte das gravuras é encontrada em rochas popularmente conhecidas como pedra sabão, que por terem características maleáveis, permitiram aquele tipo de gravura. Muitas dessas gravuras permitem interpretações diversas, por vezes relacionadas a sistemas de contagem, conforme relatado por guias de turismo no local.

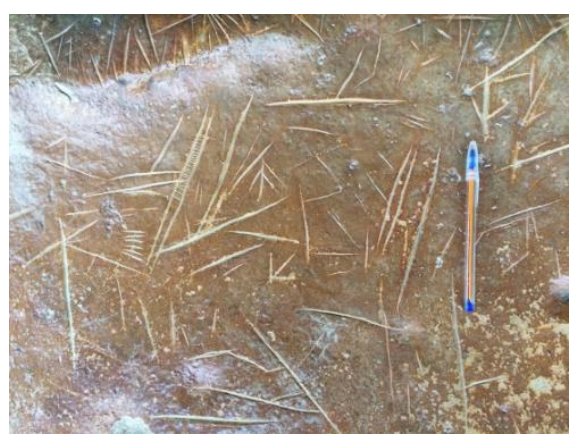

Figura 04. Gravuras rupestres, Lajedo de Soledade. Fonte: Dinária Rafaela, 2016.

Boa parte desses registros rupestres está em áreas conhecidas como ravinas, que representam formas de relevo típicas de ambientes cársticos. Sua origem e evolução estão relacionadas a diversos processos como dissolução da rocha carbonática, erosão e, por vezes, solapamento de material. Dentre as ravinas, as mais conhecidas são as ravinas da Dodora (figura 5-A), dotada de painéis com pinturas rupestres, e a do Peninha, com um acesso difícil por meio de uma escalada de 
cerca de 7 metros (figura 05-B). Ambas homenageiam pessoas que muito contribuíram para o conhecimento do local e sua preservação, salvando o Lajedo de Soledade da degradação ambiental: Maria Auxiliadora da Silva Maia (Dodora), historiadora apodiense e Geraldo Luis Nunes Gusso (Peninha), geólogo.
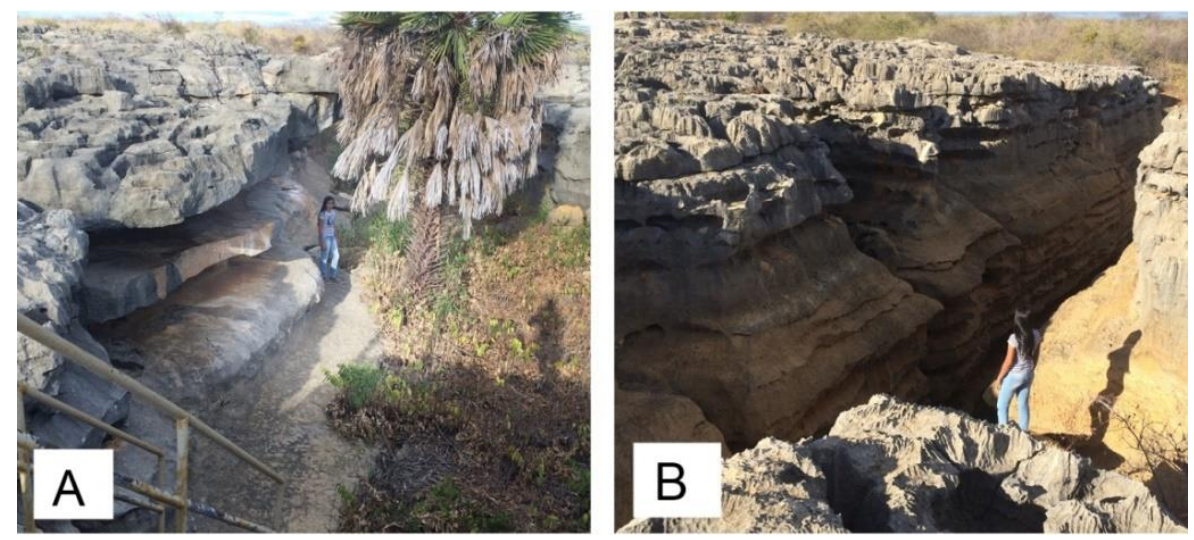

Figura 05. Ravinas da Dodora (A) e do Peninha (B), Lajedo de Soledade. Fonte: Jéssica Alves, 2016.

Além de sua importância geológica, geomorfológica e arqueológica que justificam a potencialidade geoturística do Lajedo de Soledade, há ainda a presença de sítios paleontológicos na área de estudo. Vários fósseis de mamíferos da megafauna pleistocênica já foram coletados, especialmentenas ravinas, e compreendem espécies de pequeno, médio e grande porte (PORPINO et al., 2004).

Todas essas características fazem do Lajedo de Soledade uma área de grande potencial para realizar atividades que abordem de forma educativa a geodiversidade, esse pode ser um excelente caminho para auxiliar estudantes e turistas a construírem cedo seus conhecimentos sobre a história evolutiva da Terra. Conhecer a geodiversidade de um lugar é conhecer um patrimônio único. Para BRILHA (2005, p. 40):

"[...] A educação em Ciências da Terra só pode ter sucesso se permitir o contacto directo com a geodiversidade. Quer no que respeita a actividades educativas formais, de âmbito escolar, quer a actividades educativas não formais, dirigidas ao público geral, as saídas de campo permitem à geodiversidade um extraordinário valor educativo [...]”.

O conhecimento da geodiversidade do Lajedo por meio do geoturismo pode propiciar um importante benefício para a comunidade local e para o município de Apodi, por possibilitar a geração de emprego e renda, bem como efetivar a conservação da geodiversidade e seus elementos associados. O geoturismo emerge como um expoente relacionado ao ecoturismo, inserindo um enfoque mais voltado ao ambiente físico, abiótico e, em muitos casos buscando atender preceitos de sustentabilidade que o ecoturismo não atingiu por meio de suas práticas (LOBO et al., 2012).

\section{CONSIDERAÇÕES FINAIS}


De acordo com o que foi abordado no presente artigo, fica clara a potencialidade geoturística do Lajedo de Soledade em razão de sua geodiversidade e dos seus elementos associados. Tanto devido à representatividade de sua geodiversidade, como dos valores educativo, didático, paisagístico e científico das rochas carbonáticas, das formas cársticas e dos sítios arqueológicos e paleontológicos.

Estes valores reforçam a necessidade de conservação dessa área, uma vez que não se trata de uma unidade de conservação legalmente instituída pela Lei no 9.985/2000 que trata do Sistema Nacional de Unidade de Conservação da Natureza. Sendo assim, a conservação dessa área pode ser reforçada por meio da atividade geoturística, que além de gerar renda que pode ser revertida para a manutenção do Lajedo, também promove a divulgação geocientífica facilitando as ações de preservação por meio da conscientização dos visitantes e da população local, pois só se preserva aquilo que se conhece.

Por fim, reforça-se que a atividade geoturística a ser implementada no Lajedo deve se dar de forma organizada, pautada em prévio planejamento integrado e considerar a realização de estudos de capacidade de carga ecológica e ambiental, bem como estudos de impacto ambiental que permitam o conhecimento dos impactos de forma antecipada e, assim, possibilitar a sua mitigação no decorrer da atividade. E, desse modo, garantir o sucesso da conservação desse importante patrimônio geológico, geomorfológico, arqueológico e paleontológico de Apodi e do Rio Grande do Norte.

\section{REFERÊNCIAS}

BAGNOLI, E. O Lajedo de Soledade, Apodi (RN) um exemplo de preservação do patrimônio cultural brasileiro. Revista de Arqueologia, São Paulo. p. 239-253. 1994.

BENTO, L. C. M.; RODRIGUES, S. C. O geoturismo como instrumento em prol da divulgação, valorização e conservação do patrimônio natural abiótico: uma reflexão teórica. Turismo e paisagens cársticas, Belo Horizonte, v. 3, n. 2, p. 55 - 65. 2010.

BRILHA, J. B. R. Patrimônio geológico e geoconservação: a conservação da natureza na sua vertente geológica. Porto: Palimage, 190 p. 2005.

CAÑADAS, S.; RUIZ FLAÑO, P. Geodiversidad: concepto, evaluación y aplicación territorial. El caso de Tiermes Caracena (Soria). Boletín de la A.G.E., Madrid, no 45, p. 79-98, 2007.

Companhia de Pesquisa de Recursos Minerais - CPRM. Diagnóstico do Município de Apodi. Ministério de Minas e Energia. Secretaria de Desenvolvimento Energético. Brasília, 2008.

Geodiversidade do Estado do Rio Grande do Norte. Rio de Janeiro: CPRM, 2010. Disponível em: <http://www.cprm.gov.br/publique/media/Geodiversidade_RN.pdf>. Acesso em: 16/05/2016.

EMPRESA BRASILEIRA DE PESQUISA AGROPECUÁRIA - EMBRAPA. Sistema Nacional de Pesquisa de Solos. Sistema brasileiro de classificação de solos. 2. ed. Rio de Janeiro, 306p. 2006. 
Quadro Vegetacional do Município de Apodi. Fundação Instituto Brasileiro de Geografia e Estatística - IBGE. 2002.

Demografia do Município de Apodi. Fundação Instituto Brasileiro de Geografia e Estatística IBGE. 2015.

GIL, Antônio Carlos. Como elaborar projetos de pesquisa. 4. ed. São Paulo: Atlas, 2008.

GODOY, L. H.; SARDINHA, D. S.; BERTINI, R. J.; CONCEIÇÃO, F. T.; DEL ROVERI, C. e MOREIRA, C. A. Potencial Geoparque de Uberaba (MG): geodiversidade e geoconservação.

Revista Sociedade e Natureza. Uberlândia-MG, v. 2, n. 25, p. 395-410, 2013.

INSTITUTO DE DESENVOLVIMENTO SUSTENTÁVEL E MEIO AMBIENTE - IDEMA. 2005. Disponível em: <http://www.idema.rn.gov.br/>. Acesso em: 16/05/2016.

Perfil do seu município - Apodi. Natal: IDEMA, 2008. Disponível em:

<http://www.idema.rn.gov.br/Conteudo.asp?TRAN=PASTAC\&TARG=875\&ACT=\&PAGE=\&PA $\mathrm{RM}=\& \mathrm{LBL}=>$. Acesso em: 12/04/2016.

LOBO, H. A. S.; MOREIRA, J. C. e FONSECA FILHO, R. E. Geoturismo e Conservação do Patrimônio Natural em áreas cársticas brasileiras. São Paulo-SP. Anais do IX Seminário Da Associação Nacional Pesquisa e Pós-Graduação Em Turismo. São Paulo, 2012.

MANOSSO, Fernando César. ONDICOL, Ramón Pellitero. Geodiversidade: Considerações sobre Quantificação e Avaliação da Distribuição Espacial. Anuário do Instituto de Geociências - UFRJ. vol. 35, 2012.

MARTIN, G. Dez mil anos do homem pré-histórico no Rio Grande do Norte. In: Terra Potiguar. Natal, Bustamantes Editores, p. 24-39. 2000.

MARTINS, Rosilda Baron. Metodologia cientifica. Curitiba: Juruá, 278p. 2010.

MEDEIROS, Wendson Dantas de Araújo. OLIVEIRA, Frederico Fonseca Galvão de. Geodiversidade, geopatrimônio e geoturismo em Currais Novos, NE do Brasil. Mercator, Fortaleza, v. 10, n. 23, p. 59-69, set./dez. 2011.

NASCIMENTO M. A. L., RUCHKYS Ú. A., MANTESSO NETO V. Geodiversidade, Geoconservação e Geoturismo: trinômio importante para proteção do patrimônio geológico. Sociedade Brasileira de Geologia, São Paulo, 82p. 2009.

PORPINO, K. O.; SANTOS, M. F. C. F.; Bergqvist, L. P. Registros de mamíferos fósseis no Lajedo de Soledade, Apodi, Rio Grande do Norte. Revista Brasileira de Paleontologia, 7(3): 349-358. 2004.

SECRETARIA DE ESTADO DO MEIO AMBIENTE E DOS RECURSOS HÍDRICOS DO RN SEMARH. Plano Estadual de Recursos Hídricos: relatório síntese. Natal, 2007. Disponível em: <http://www.serhid.rn.gov.br>. Acesso em: 14/04/2016.

SILVA, J. R. B.; PERINOTTO J. A. J. O geoturismo na geodiversidade de Paraguaçu Paulista como modelo de geoconservação das estâncias. Revista Global Tourism, v. 3, n. 2, 40 p., 2007.

SOCIEDADE BRASILEIRA DE ESPELEOLOGIA - SBE. Cavernas do Brasil. Disponível em: <http://www.sbe.com.br/cavernas_maiores.asp?txtestado=RN>. Acesso em: 19/05/2016.

Recebido: 14/08/2016

Aceito para publicação em: 01/10/2016 